\title{
A comprehensive American Association for Thoracic Surgery quality program for the 21 st century
}

Eugene H. Blackstone, MD, ${ }^{\mathrm{a}}$ Julie Swain, MD, ${ }^{\mathrm{b}}$ Ken McCardle, MS, ${ }^{\mathrm{c}}$ and David H. Adams, MD, ${ }^{\mathrm{b}}$ for the Governance Committee, American Association for Thoracic Surgery Quality Assessment Program

From the ${ }^{a}$ Departments of Thoracic and Cardiovascular Surgery and Quantitative Health Sciences, Cleveland Clinic, Cleveland, Ohio; 'bepartment of Cardiovascular Surgery, Icahn School of Medicine, New York, NY; and ${ }^{\mathrm{c}}$ Department of Clinical Operations, Mount Sinai Health System, New York, NY.

Supported in part by the American Association for Thoracic Surgery.

Read at the 99th Annual Meeting of The American Association for Thoracic Surgery, Toronto, Ontario, Canada, May 4-7, 2019.

Received for publication July 11, 2019; revisions received July 11, 2019; accepted for publication July 12, 2019. Address for reprints: Eugene H. Blackstone, MD, Department of Thoracic and Cardiovascular Surgery, Cleveland Clinic, 9500 Euclid Ave/Desk JJ40, Cleveland, OH 44195 (E-mail: blackse@ccf.org).

J Thorac Cardiovasc Surg 2019;158:1120-6 $0022-5223 / \$ 36.00$

Copyright (C) 2019 Published by Elsevier Inc. on behalf of The American Association for Thoracic Surgery https://doi.org/10.1016/j.jtcvs.2019.07.017

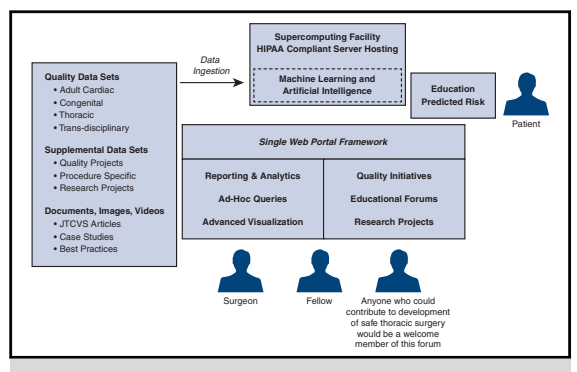

Schematic of envisioned AATS Quality Assessment Program.

Central Message

Using modern data concepts and risk assessment, real-time feedback, and a collaborative platform, the 21st century AATS Quality Assessment Program will answer the physician's question, how am I doing?, the patient's question, what are my chances?, and the profession's question, how can I improve? are obliged to populate myriad data repositories. In the early 2000s, my Department made a large, painful investment to co-develop a system that minimized duplicate data entry while efficiently reporting hundreds of nonuniform data elements to multiple, highly variable platforms. That only illustrates challenges on the data entry side. Inability to analyze actionable feedback in anything approaching real time is retarding the advancement of our profession by stunting innovation and collaboration.

As a way out of this morass, it is tempting to emulate New York State's database, which is a lean, parsimonious greyhound compared with the lumbering oxen that surround it. I realize I'm hopelessly biased after almost 30 years of experience within it, but I also recognize that nothing is perfect: New York State's database is too lean for some purposes, and its meticulous auditing generates a crippling 2- to 3-year delay in feedback.

When no perfect solution exists, it is tempting to pick the lesser among many existing evils and work within that, assuming we could agree on what comes closest. My experience suggests that won't work. For example, New YorkPresbyterian Hospital/Columbia University Medical Center purchased an outpatient electronic medical record (EMR) system from one company and an inpatient EMR from another, cleverly creating a Tower of Babel with two systems that couldn't communicate. Then the two companies merged! Problem solved, we assumed. We were assured that all those proprietary moats and drawbridges would vanish overnight! Not so, as it turned out.

Even with the best of intentions, software and hardware platforms that evolve independently for any meaningful period of time narrow their range of mutation and lose the ability to interbreed. The right solution requires something more revolutionary than evolutionary. That, I believe, is where we are.

—Craig R. Smith, MD President, American Association for Thoracic Surgery, 2011-2012

\section{AMERICAN ASSOCIATION FOR THORACIC SURGERY QUALITY ASSESSMENT PROGRAM}

Gerald O'Connor, for more than 20 years, was Research Director of one of the most effective quality improvement programs in cardiac surgery, the Northern New England Cardiovascular Disease Study Group. In his article on Physician Leadership in Cardiac Outcomes Reporting, ${ }^{1}$ he had this to say:

We have learned some lessons. Most important is to keep it simple and get it right. Our primary data collection form is one page, one side.

...the data and the reports are a means not an end. The data are for action. They are for solving problems not for admiring them.... 
These data can provide answers to some of the most important questions in cardiac surgery:

The physician asks: "How am I doing?"

The patient asks: "What are my chances?"

The profession asks: "How can we improve?"

Now more than 30 years later, cardiothoracic programs and their institutions expend enormous energy and resources maintaining and feeding multiple professional-, government-, and payor-mandated registries. But have we forgotten O'Connor's 3 critically important questions?

Given the enormous strides in communication, the internet, and computer technology on the one hand and data science with machine learning and artificial intelligence on the other, what would a quality assessment program, squarely focused on those questions, look like if it were developed from the ground up in the 21st century? An American Association for Thoracic Surgery (AATS) task force has spent the last year trying to answer this question. This essay answers the question by introducing you to the AATS Quality Assessment Program for the 21st century. Its 3 central components are modern data concepts and risk assessment, realtime feedback, and a platform for collaboration (Figure 1).
In 2019, with cloud computing, semantic interoperability, and blockchain technology, data concepts are rapidly evolving, and machine learning and artificial intelligence are providing data analytics barely hinted at 30 years ago. How does this help all of us, our patients, and our specialty?

\section{DATA SET FOCUSED ON QUALITY}

We propose a modern cloud-hosted data structure focused on quality. It will be composed of core quality data sets of approximately 150 variables, which we believe would be right-sized for adult cardiac, general thoracic, and pediatric and congenital heart disease.

Each core quality data set will consist of preoperative data, including administrative variables and demographics, clinical status of the patient at operation, and comorbidities. Operative data will consist of major components, such as coronary artery bypass grafting $(\mathrm{CABG})$, valve repair or replacement, ablation operations for atrial fibrillation or flutter, thoracic aorta procedures, and any combination of these. Only important process details that relate to quality will be collected, such as when antibiotics are given and cardiopulmonary bypass time. And quality outcomes will comprise the metrics-metrics that matter and are actionable.

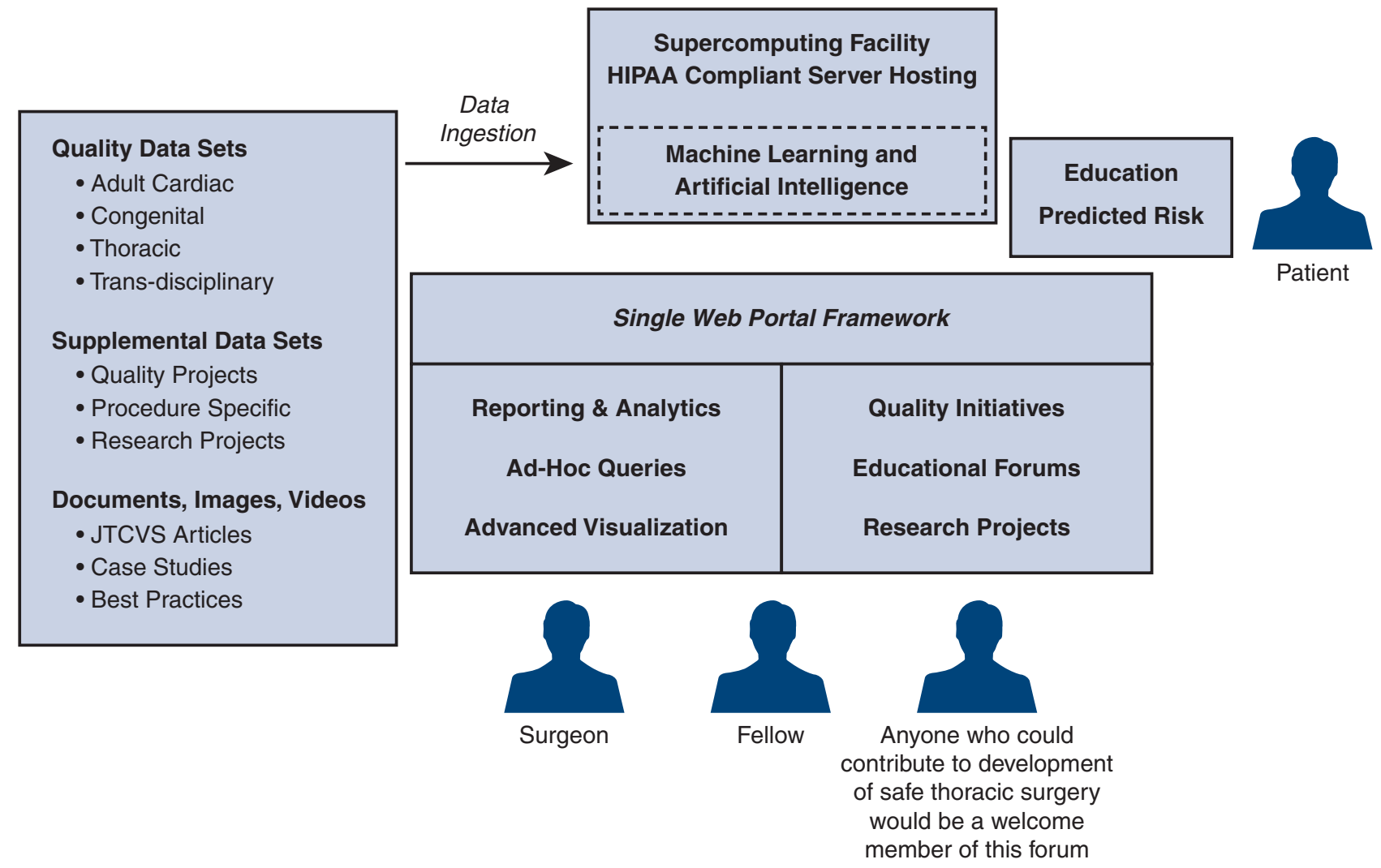

FIGURE 1. Schematic of envisioned AATS Quality Assessment Program. JTCVS, The Journal of Thoracic and Cardiovascular Surgery; HIPAA, Health Insurance Portability and Accountability Act. 
This approach provides opportunities for cost and error reduction. A streamlined set of core data elements will reduce abstraction costs by as much as $75 \%$ or more. Automated abstraction whenever possible from the electronic medical record and other sources will reduce both cost and transcription errors. This will be facilitated and accelerated by ever-improving capture of discrete data in the electronic medical record by using controlled clinical terminologies and ontologies, such as SNOMED CT, and through increasing specificity of medical billing codes, such as the upcoming release of International Classification of Diseases, 11th Revision. Clinical sites will not need outside vendors, reducing information technology costs.

The AATS Task Force is actively exploring, developing, and testing machine-learning risk assessment tools that are more powerful than logistic regression, which was developed in the 1960s by Jerome Cornfield and colleagues for the Framingham Heart Study. ${ }^{2,3}$ Already there are machine-learning methods for automatically learning as data accrue instead of infrequently updated risk models. These methods account for even complex interactions among predictor variables. ${ }^{4,5}$ Thus, we have been able to demonstrate that they will allow us to encompass all adult cardiac operative procedures in a single risk-prediction algorithm, rather than encompassing only selected procedures with separate models.

These advanced methods will provide the answer to the individual patient's query "What are my chances?" Consider a hypothetical 70-year-old diabetic, hypertensive man with aortic stenosis, mitral regurgitation, and 3vessel coronary artery disease experiencing New York Heart Association functional class III symptoms. Currently, his predicted risk, based on national lag data, is $4.8 \%$. Machine learning would provide more specific prediction for this man's risk, based on continuous updating, including the last cases entered. For example, we envision a surgeon consulting with this hypothetical patient, sharing an upto-date set of personalized predicted risks based on the national average $(4.4 \%)$, the hospital system's average $(4.0 \%)$, the hospital's average $(3.5 \%)$, and the surgeon's own average $(2.4 \%)$.

Again in the words of O'Connor, ${ }^{1}$ we ask, based on outcomes and analytics, "How am I doing?" We must have

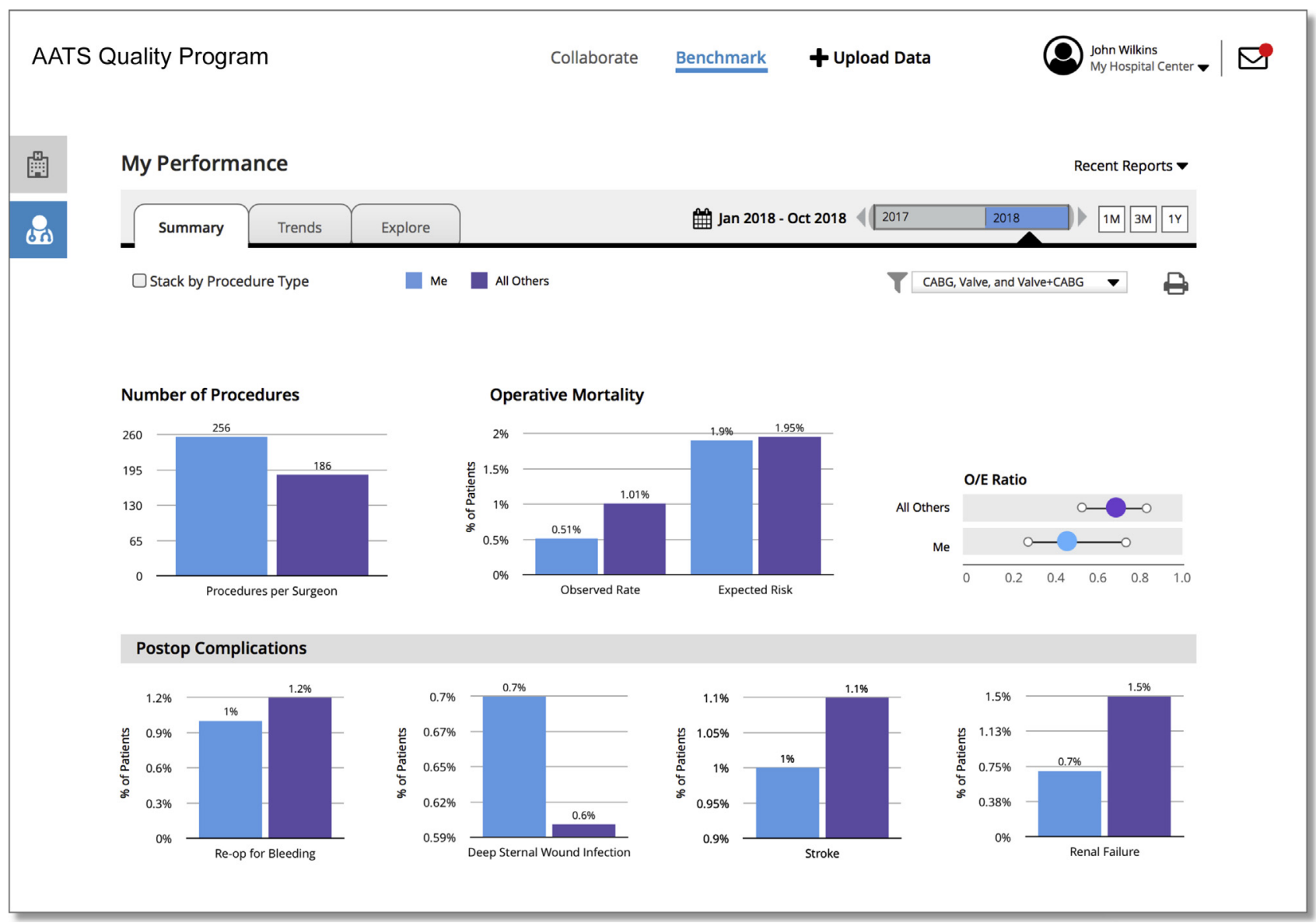

FIGURE 2. Hypothetical on-demand report of surgical performance for a surgeon (blue) compared with all others (purple). Web mockup by HUBZero. $O / E$, Observed/expected. 

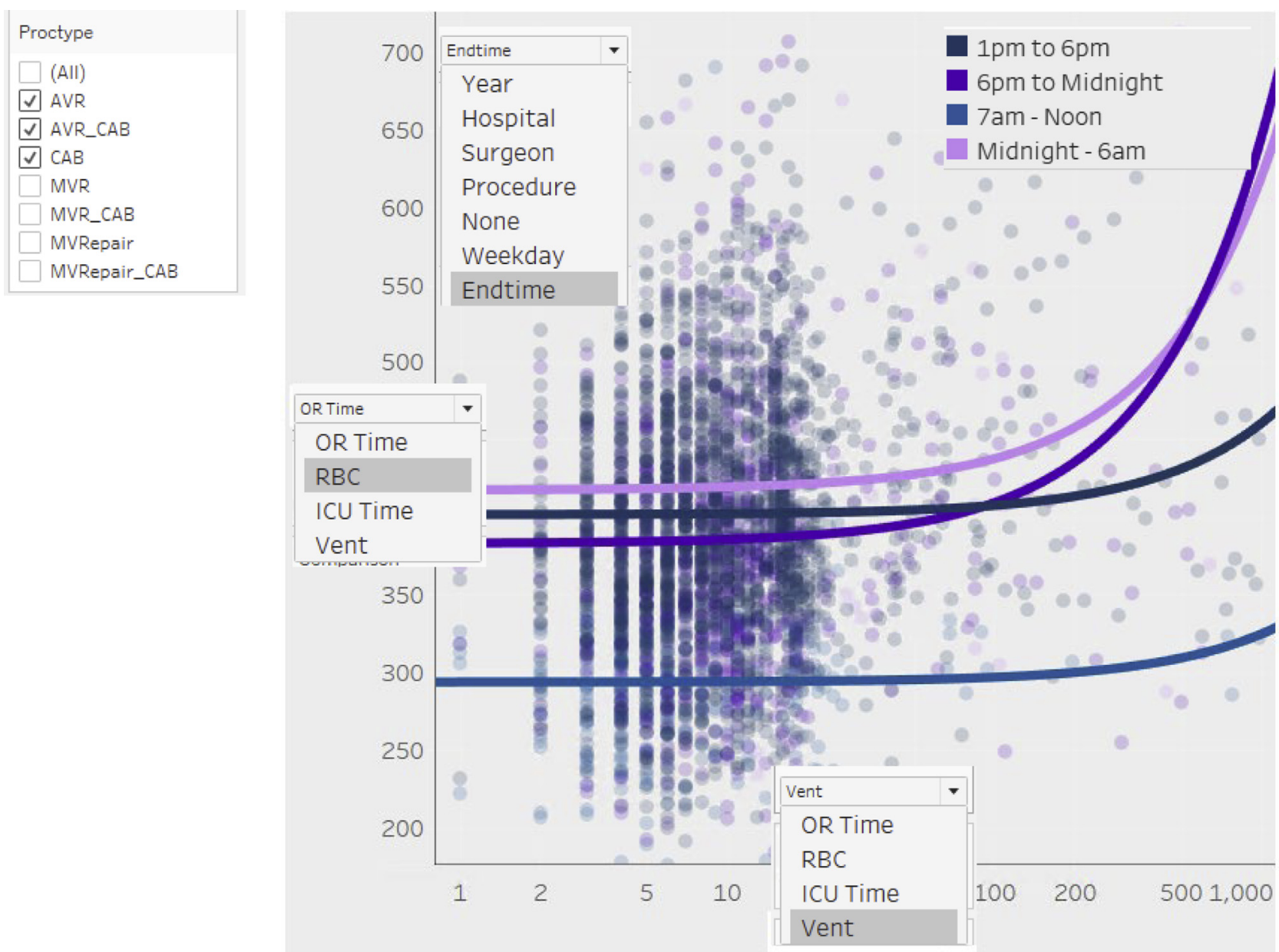

FIGURE 3. Hypothetical advanced visualization graph of procedure end time, red blood cell use, and ventilator time according to 6-hour shifts during a specified time period. $A V R$, Aortic valve replacement; $C A B$, coronary artery bypass; $M V R$, mitral valve replacement; $M V$, mitral valve; $O R$, operating room; $R B C$, red blood cells; $I C U$, intensive care unit.

rapid feedback of individual surgeon results to take action when needed. How does this help all of us, our patients, and our specialty?

\section{REAL-TIME FEEDBACK}

In this 21 st century, we should expect real-time reporting, on demand, anytime, anywhere. We should be provided extensive site-tailored dashboards of our performance. We also need to know how we are doing for all of our operations, risk adjusted for individual-surgeon case mix. Figure 2 represents how one such report looks for a specific procedure benchmarking a surgeon's performance against peers. It shows the number of cases, operative mortality, and postoperative complications.

Likewise, we will be able to benchmark process metrics compared with peers, such as operating room time for a given procedure, ventilation hours, and transfusions-all risk adjusted (Figure 3). Today there are great advances in data visualization. Thus, we envision 3-dimensional charts of processes such as the relation between operating room end time, duration of the operation, and ventilation hours.

What about tracking geographical referral patterns? Where do our patients come from for operations such as aortic valve replacement, isolated $\mathrm{CABG}$, and aortic valve replacement plus CABG? Patient ZIP code or even census track will be incorporated (Figure 4).

\section{PLATFORM FOR COLLABORATION}

Again in the words of $\mathrm{O}^{\prime}$ Connor $^{1}$ : How can we improve as a profession?

Success of the Northern New England program rested on multi-site collaboration. Multidisciplinary teams made structured visits to other medical centers, shared best practices, and gained ideas for changes they believed could accelerate the rate of improvement in patient outcomes. ${ }^{1}$ How does that help all of us, our patients, and our specialty?

What if there were virtual multidisciplinary teams with whom you could communicate in an online forum? 


\section{My Case Distribution}

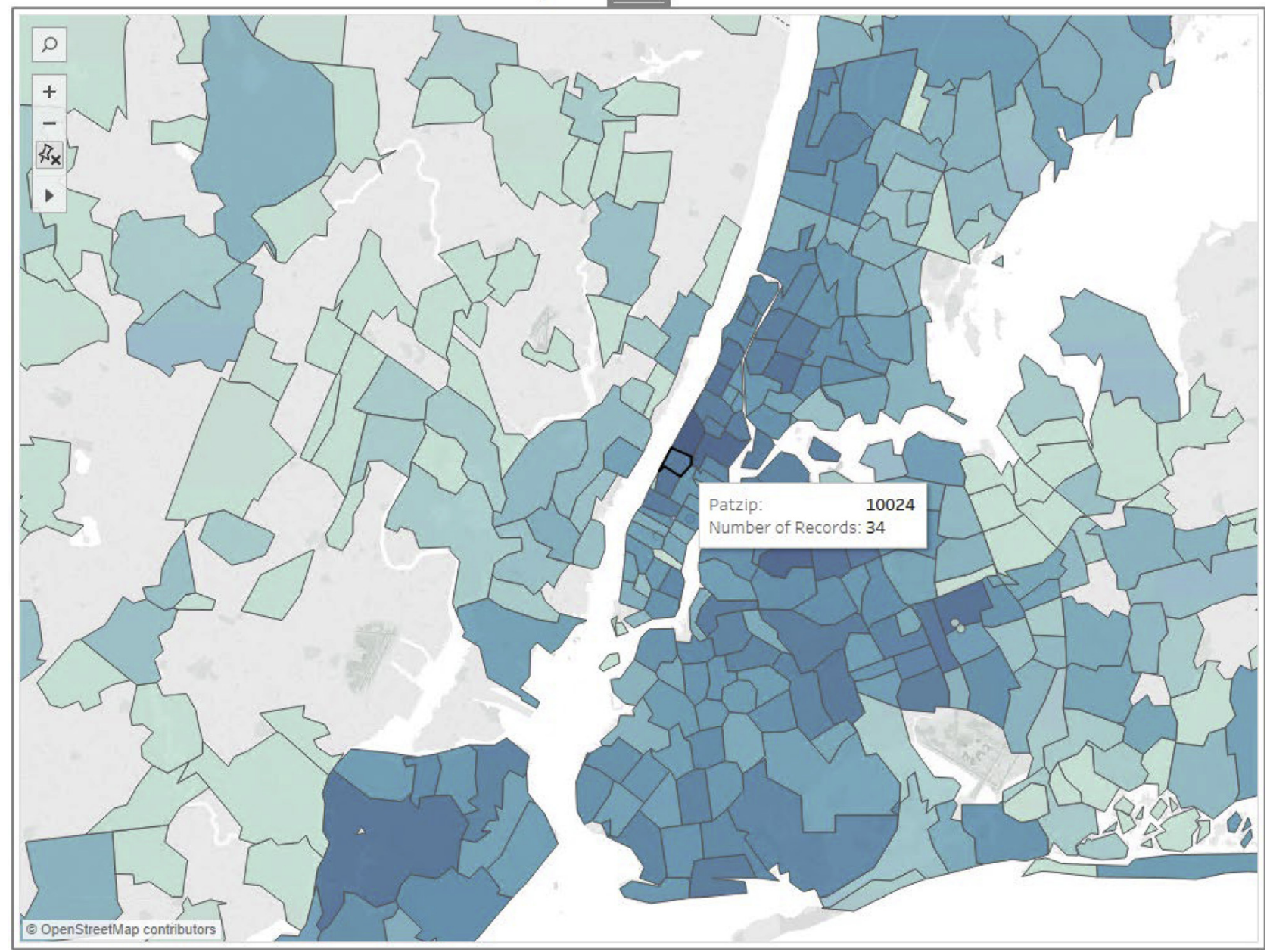

FIGURE 4. Hypothetical geographical heat map of patient referral pattern for aortic valve replacement, isolated CABG, and combined aortic valve replacement and CABG.

Consider a peer report of performance (Figure 5, A). Overall, the metrics may make one feel good, but focus your attention on the bottom set of graphs and specifically the one indicated by the blue box: stroke. In this illustration, stroke after isolated $\mathrm{CABG}$ and isolated valve procedures is much higher for the reported surgeon than for peers. This is alarming! Can this surgeon get some ideas from the peer group about how to decrease the occurrence of this devastating complication?

The surgeon presses the little icon representing his or her peer discussion forum and sends out a message. "Hi, everyone! I was just looking at my performance charts and noticed...." There may be responses from peers about factors that have been found to increase or decrease the risk for stroke-imaging, cannula placement, aortic clamping or not-and that may help this surgeon avoid these strokes (Figure 5, $B$ ).

Thus, we are proposing a vision of resources and collaborative discussions focused on how we improve. This may include sharing best practices in forums where you can ask, "What am I doing wrong?" or "How do I get started on a quality improvement program to reduce my procedurerelated strokes?" There may be blogs where experienced surgeons can tell everyone what worked and what didn't and why. We envision multiple sites connecting themselves as a community, with no geographical boundaries, to develop and execute quality initiatives to help us improve.

Multi-site collaboration should lead to multi-site research. For this, we propose that provision be made for cooperating sites to gather detailed data on specific types of operations for quality improvement and research. Collaboratives could be formed for investigator-initiated clinical trials or commercially sponsored trials.

It is the 21 st century, and computer technology has made the world small. There is no reason not to encourage international collaboration. The reality is also that lines are increasingly blurred among catheter-based structural heart interventions, hybrid procedures, and pure surgical 


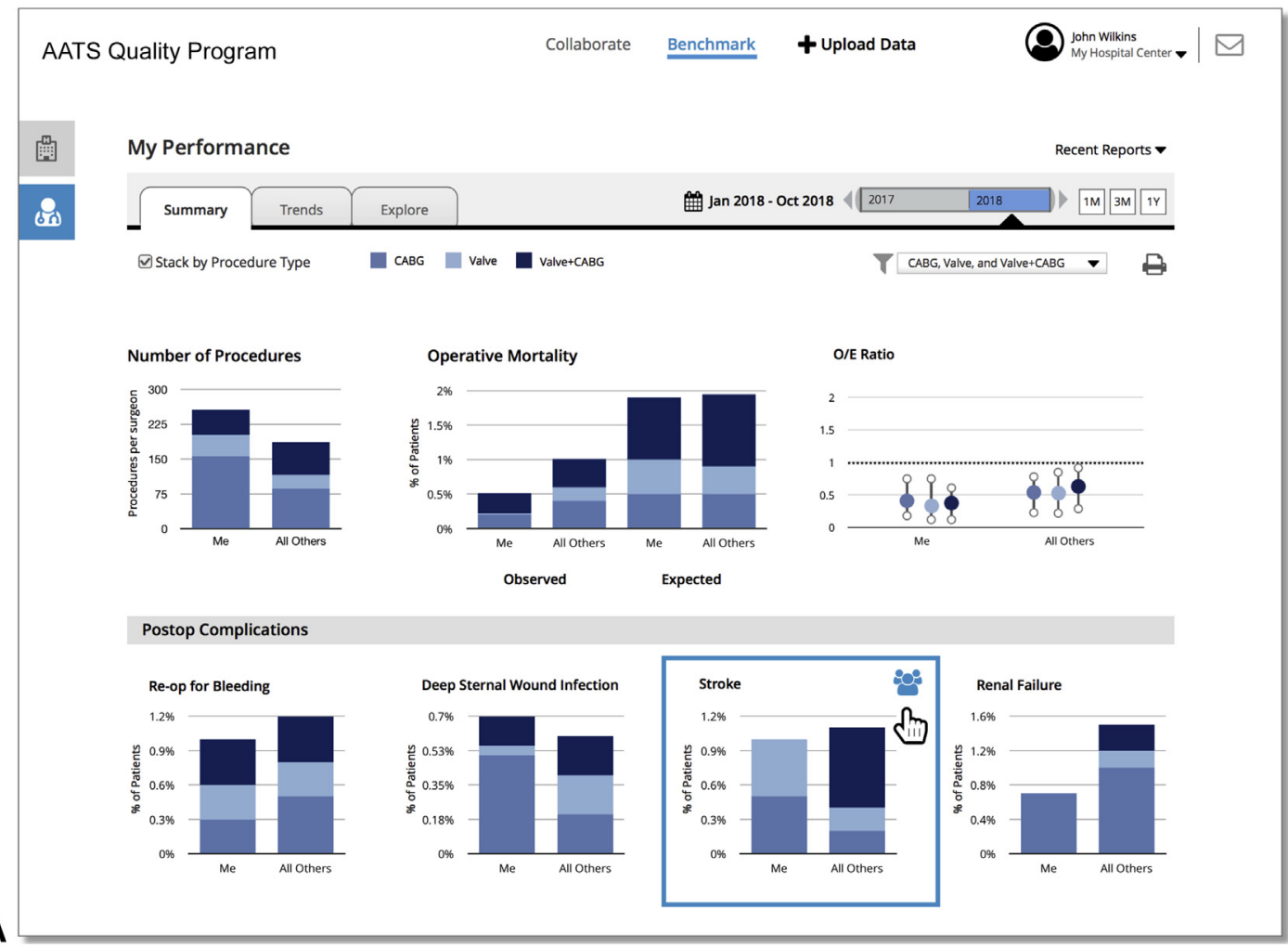

A

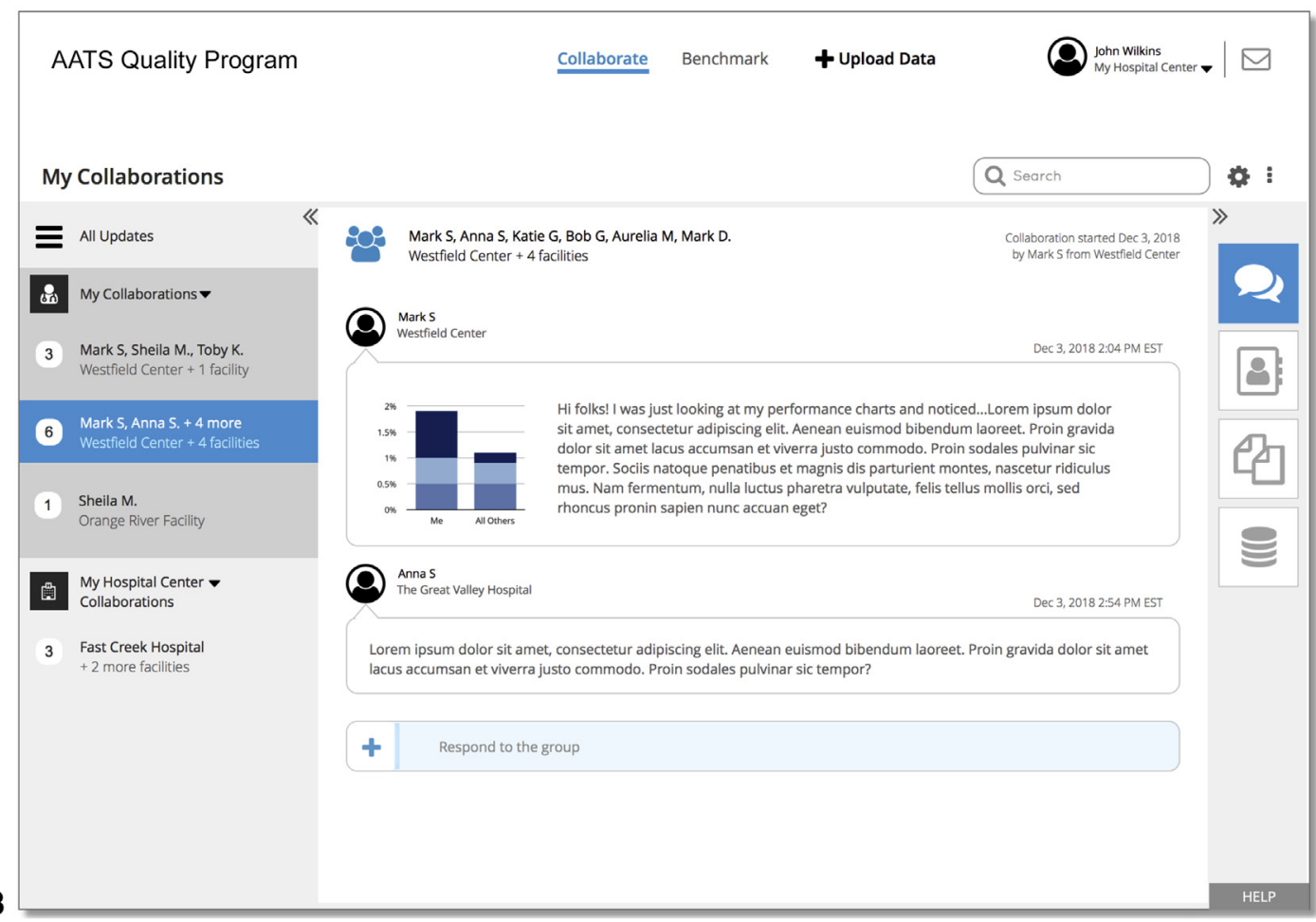

FIGURE 5. Hypothetical collaboration for recognized excess strokes for CABG and valve procedures. Web mockup by HUBZero. A, Data display. Blue box highlights the excess strokes. Within the highlighted area is an icon that will link to my peer quality discussion group. B, Dialog with my quality peer discussion group about my excess strokes. $C A B G$, Coronary artery bypass grafting; $O / E$, observed/expected. 
interventions. Willy Meyer, who envisioned the American Association for Thoracic Surgery, invited the internist, anesthetist, physiologist, radiologist, anatomist, experimental worker, pathologist, endoscopist, infectious disease specialist, and surgeon to join together in combating thoracic diseases. Anyone who could contribute to the development of safe thoracic surgery would be a welcome member of this forum.

Our vision for the 21st century is similarly transdisciplinary. Transcatheter valve interventions in adults are a natural fit, but so are catheter-based interventions and reinterventions for congenital heart disease. We are creating a platform that will serve all cardiovascular and thoracic procedures in the future, not purely open surgical procedures.

\section{THE QUESTION ANSWERED}

Here you have the answer to the question addressed by our AATS taskforce: "What would a quality assessment program look like if it were developed from the ground up in the 21st century?" To the surgeon asking "How am I doing?" it will provide real-time feedback of results on demand, anywhere, anytime. It will provide site-specific and surgeon-specific dashboards for benchmarking. It will generate user-initiated graphical trends and relationships using advanced analytics and visualization.

For the patient asking "What are my chances?" we will provide risk assessment across all procedures, providing individualized and site-specific prediction of risk for counseling and informed consent. Prediction of risk will exploit machine learning and advanced analytics to provide accurate prediction of outcomes that we envision will facilitate precision medicine: the right procedure for the right patient at the right time. ${ }^{6,7}$ It will use continuous learning, which produces a living algorithm for predicting risk.

To us as a profession, "How can we improve?" We propose a platform for multi-site collaborative efforts to improve quality. It would include forums, specialty data modules, and research. We envision it to be international and trans-disciplinary.

\section{WHY SHOULD YOU SUPPORT THE NEW AMERICAN ASSOCIATION FOR THORACIC SURGERY QUALITY ASSESSMENT PROGRAM?}

It can give you the information that you and your patients need at low cost. It will be available 24/7/365 for self-service data analytics. The latest data science methods will be applied to provide personalized risk assessment. It will engender improved peer-to-peer collaboration without geographic boundaries.

Who has been involved to this point in developing this vision? Below we list the members of the task force governance committee in alphabetical order, the clinical advisors, and the biostatistics and data science experts who have prototyped methodology for us. In the coming year, the tools and platform will be completed and tested, and we anticipate a staged roll-out to the cardiothoracic community in 2020. We hope all of you will join us in this effort to enhance quality and progress in our specialty.

\section{Task Force Members}

Governance Committee: Dr David Adams (Chair), Dr Eugene Blackstone, Dr Pedro del Nido, Dr David Jones, Ken McCardle, MS, Dr Marc Moon, Dr Jeffrey Rich, Dr Hartzell Schaff, Dr Craig Smith, Dr Vaughn Starnes, Dr Lars Svensson, and Dr Julie Swain.

Clinical Advisors: Dr Ani Anyanwu, Dr Joseph Coselli, Dr Ralph Damiano, Dr Tirone David, Dr Ismail El-Hamamsy, Dr Marc Gillinov, Dr Robert Michler, Dr Sudish Murthy, and Dr Eric Roselli.

Biostatistics/Data Science: Hemant Ishwaran, PhD, Min $\mathrm{Lu}, \mathrm{PhD}$

\section{Conflict of Interest Statement}

Authors have nothing to disclose with regard to commercial support.

\section{References}

1. O'Connor GT. Physician leadership in cardiac outcomes reporting. Ann Thorac Surg. 2000;70:693-4.

2. Truett J, Cornfield J, Kannel W. A multivariate analysis of the risk of coronary heart disease in Framingham. J Chronic Dis. 1967;20:511-24.

3. Walker SH, Duncan DB. Estimation of the probability of an event as a function of several independent variables. Biometrika. 1967;54:167-78.

4. Ishwaran H, Blackstone EH, Hansen CA, Rice TW. A novel approach to cancer staging: application to esophageal cancer. Biostatistics. 2010;10:603-20.

5. Ishwaran H, Kogalur UB, Blackstone EH, Lauer MS. Random survival forests. Ann Appl Stat. 2008;2:841-60.

6. Lu M, Sadiq S, Feaster DJ, Ishwaran H. Estimating individual treatment effect in observational data using random forest methods. J Comput Graph Stat. 2018;27: 209-19.

7. Tonelli MR, Shirts BH. Knowledge for precision medicine: mechanistic reasoning and methodological pluralism. JAMA. 2017;318:1649-50. 